\title{
A Review on the Functionality of Nanomaterials in 2d and 3d Additive Manufacturing
}

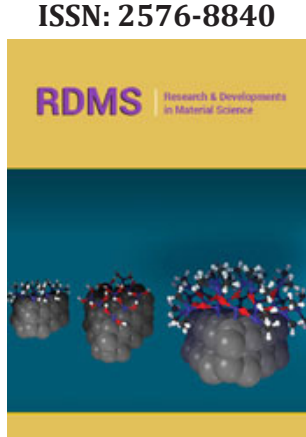

*Corresponding author: Markos Petousis, Mechanical Engineering Department, Hellenic Mediterranean University, Greece

Submission: 鲇 October 05, 2020

Published: 侮 October 15, 2020

Volume 14 - Issue 2

How to cite this article: Markos Petousis1 ,Lazaros Tzounis, Nectarios Vidakis. A Review on the Functionality of Nanomaterials in 2d and 3d Additive Manufacturing. Res Dev Material Sci. 14(2). RDMS.000833. 2020. DOI: $10.31031 / R D M S .2020 .14 .000833$

Copyright@ Markos Petousis. This article is distributed under the terms of the Creative Commons Attribution 4.0 International License, which permits unrestricted use and redistribution provided that the original author and source are credited.

\author{
Markos Petousis ${ }^{1 *}$,Lazaros Tzounis ${ }^{2}$ and Nectarios Vidakis ${ }^{1}$ \\ ${ }^{1}$ Mechanical Engineering Department, Hellenic Mediterranean University, Greece \\ ${ }^{2}$ Department of Materials Science \& Engineering, University of Ioannina, Greece
}

\begin{abstract}
Additive manufacturing (AM) is a process based on the sequential addition of material layers, allowing thus to print either 2D parts (thin or thick films substrate assisted and obtained then as self-standing films or supporting films/ coatings) or bulk 3D parts consisting of different materials with variable physical and chemical properties. The Global sales in 3D printing (products and services) rose by $21 \%$ from 2017, reaching 7B in 2018. Various techniques are available and belong to the family of 3D printing of solid materials, while the most well-known ones are the electron beam freeform fabrication, the direct metal laser sintering, and the fused filament fabrication (FFF). Due to the unique possibility to manufacture complex 3D objects layer by layer, as well as due to the relatively low-cost 3D printers available in the market nowadays, AM utilising nanomaterials could be employed in new ways toward greater control over material properties across part dimensions. The multifunctionality endowed through nanomaterials' incorporation as additives can further extend capabilities of nanocomposites to i.e. by-design and patient specific biomedical equipment and personalised medicine applications, tuned and tailored gradients in electrical and thermal conductivity, increased strength and reduced weight, photonic emissions tunable for wavelength, etc., all of which are elaborated in this mini review article. In specific, FFF 3D printing method that a main focus is given herein could allow direct 3D printing of nano enabled thermoplastic filaments endowing the nanocomposite's functionality to the bulk 3D printed derived objects.
\end{abstract}

Keywords: Three-Dimensional (3D) printing; Rapid prototyping; Nanomaterials; Nanotechnology; Additive manufacturing; Two-Dimensional (2D) printing; Polymers; Nanocomposites

\section{Introduction}

Two-dimensional (2D) and three-dimensional (3D) printing processes have received significant attention as additive manufacturing technologies amongst others [1,2]. 2D and 3D printing are additive manufacturing (AM) processes based on sequential addition of (nano-) material layers allowing to print either 2D parts (thin or thick films/ layers as self-standing films or coatings) or bulk 3D parts and components made of different (nano-)materials with variable physicochemical properties [3,4]. Namely, the global sales in 3D printing (products and services) rose by $21 \%$ from the market in 2017 reaching $7 \mathrm{~B} \$$, while the total AM market only for the Automotive sector is expected to grow from 1.5B€ in 2018 to $5.3 \mathrm{~B} €$ in 2023 and $12.6 \mathrm{~B} €$ in 2028.

\section{Roll-to-roll (R2R) and sheet-to-sheet (S2S) 2D additive manufacturing}

The 2D AM processing could be a continuous process otherwise defined as roll-to-roll (R2R) or sheet-to-sheet (S2S), both of which allow a continuous deposition of materials as inks/ pastes, melts, etc. onto rigid or flexible substrates (glass, plastic, metallic foils, textiles, etc.). In a R2R process, the materials are deposited in motion between two moving rolls named as unwinder and winder. R2R is an essential substrate-based manufacturing process in which additive (e.g. printing methods as for instance ink-jet, slot-die, etc.) and/ or subtractive technologies (e.g. laser scribing) can be employed to build 2D components in a continuous manner.

R2R could offer cost-effective and high production rates of mass quantities, combining, in a continuous manner, different technologies towards the production of rolls with a finished product. Today, R2R processing is applied in numerous manufacturing fields such as i) coating of textiles (e.g. using a bath coating technology otherwise known as dyeing process) 
[5], ii) prepregs for advanced CFRP structural composites (bath or slot die deposition of epoxy onto fabrics) [6], iii) packaging i.e. smart packaging (e.g. slot-die, gravure, bath coating, screen printing, flexography of inks, varnishes, etc.) [7], flexible and largearea printed electronics (e.g. slot-die, gravure, bath coating, screen printing, flexography, ink-jet printing of electronic inks and pastes) [8-10], thin-film batteries [11] and (bio-)electrodes (e.g slot-die, screen printing) [12], textiles for wearables (e.g. ink-jet printing, screen printing and flexography) [13], membranes (e.g. slot-die, etc.) [14], etc. The global R2R technology market is expected to reach $35.69 \mathrm{~B} \$$ to 2023 expanding at a compound annual growth rate (CAGR) of $13.5 \%$ from 2015 to 2023.

Figure 1 demonstrates (a) a schematic of a R2R AM process, as well as (b) a representative R2R printing/ coating line produced by FOM company (FOM, Denmark); while in (c) a schematic of a S2S printing coating AM process is depicted and in (d) a S2S printing slot-die and blade coating machine produced by COATEMA printing technologies company (Coatema, Germany).

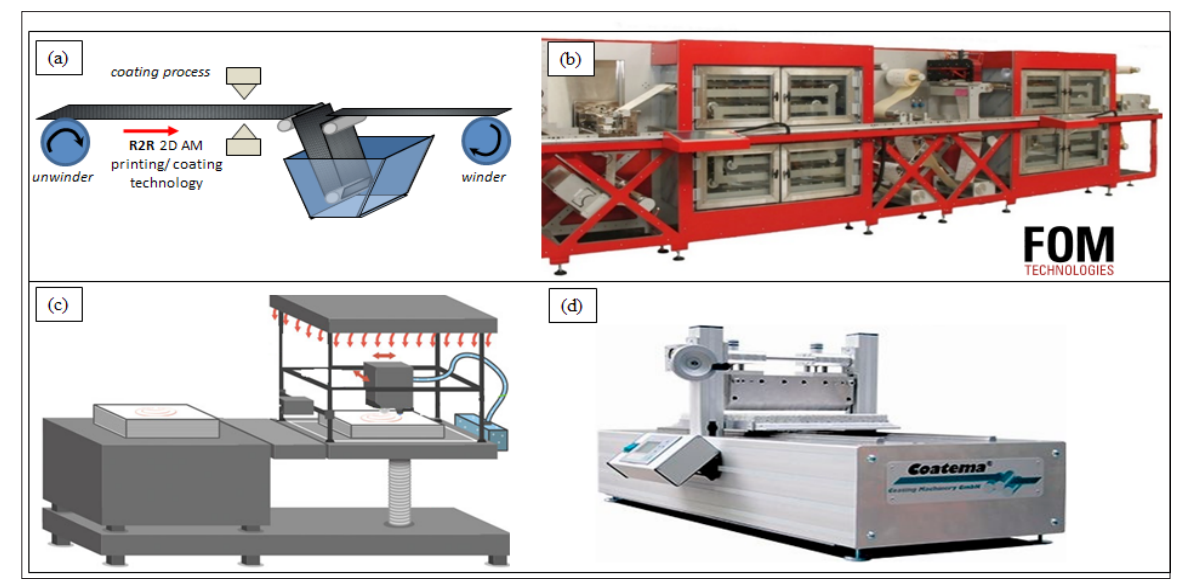

Figure 1: (a) Schematic of a R2R AM process, as well as (b) a representative R2R printing/ coating AM line; (c) a schematic of a S2S printing coating AM process, and (d) a S2S printing slot-die and blade coating machine.

\section{Three dimensional (3D) additive manufacturing}

3D printing is nowadays one of the most promising additive manufacturing (AM) processes based on sequential addition of material layers allowing to manufacture bulk 3D parts with tailored properties i.e. mechanical, thermal, electrical, etc. [15]. The first 3D print was reported by Hideo Kodama in 1982 [16]. Since then, 3D printers have become much more accessible in the engineering academic community as well as end-product manufacturing companies with numerous achievements through process optimization, etc. 3D printers are now able to print different materials including metals, wood products, and engineered thermoplastics, such as Polylactic Acid (PLA), Polypropylene (PP), Polyether Ether Ketone (PEEK), and others. Specifically, there are various techniques for printing solid materials in 3D, including, as shown in Figure 2a: inkjet 3D printing, Figure 2b: fused deposition modeling (FFF), Figure 2c: stereolithography (SL), Figure 2d: selective laser sintering (SLS), electron beam freeform fabrication, direct metal laser sintering, among others [16].

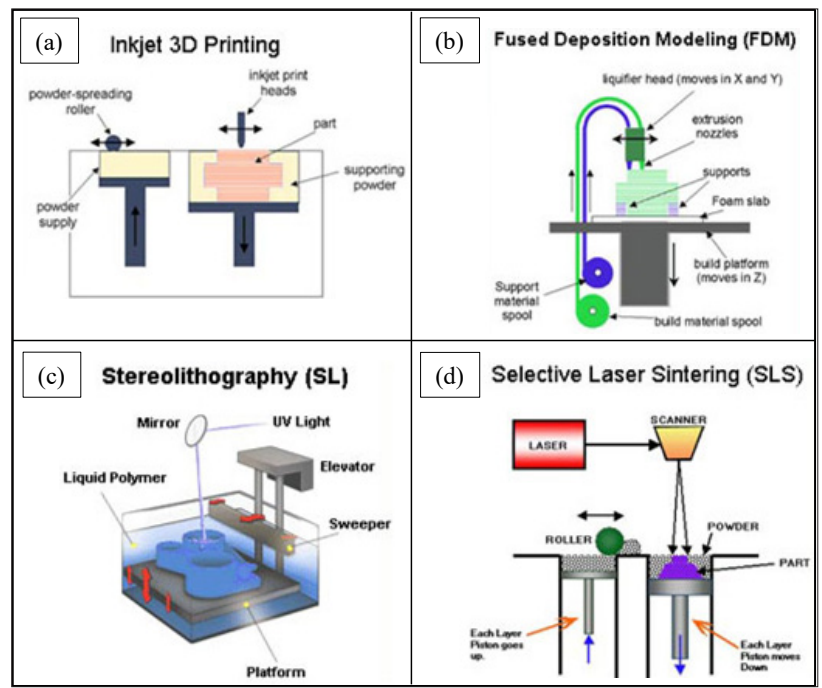

Figure 2: (a) inkjet 3D printing, (b) fused deposition modeling (FFF), (c) stereolithography (SL), and (d) selective laser sintering (SLS). 


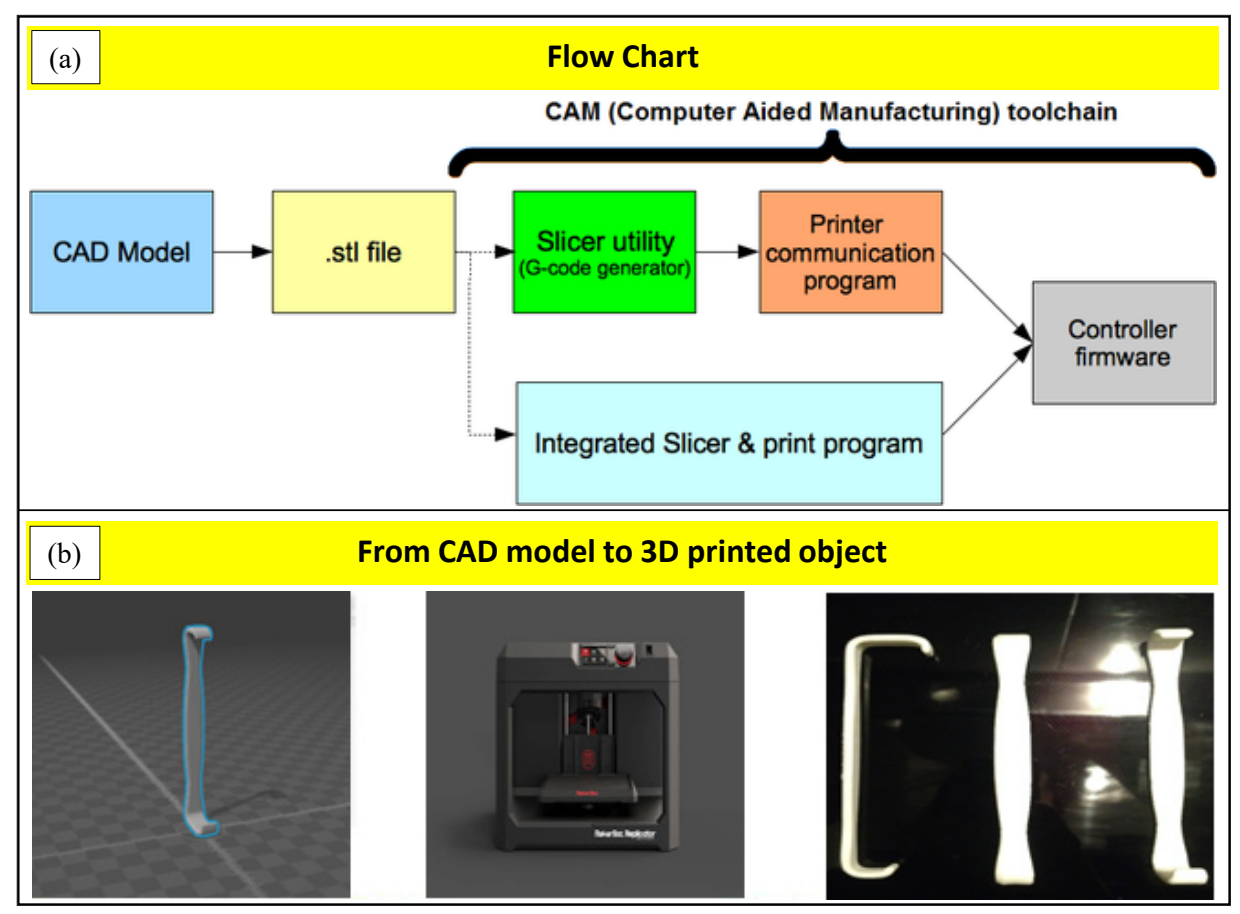

Figure 3: (a) Flow chart of a 3D printing AM process including the generation of the CAD model towards exporting it in an stl file capable of being communicated with most of the 3D printer software the printing process; (b) CAD model of a surgery retractor as well as a 3D FFF printer deployed to print the objects shown in the right hand-side of the image.

Figure 3 demonstrates (a) the flow chart of a 3D printing $\mathrm{AM}$ process including the generation of the CAD model (in a CAD specific software e.g. Solidworks, AutoCAD, 3D Builder, etc.) towards exporting it to an stl file capable of being communicated with most of the 3D printer software the printing process (printing process has to be simulated, process parameters to be chosen etc. from the printer software). In Figure 2b, a CAD model of a surgery retractor is depicted, as well as a 3D Fuse Filament Fabrication (FFF) printer for thermoplastic materials (MakerBot Inc. USA) used to print the objects shown in the right hand-side of the image.

\section{Nanotechnology and applications}

Nanoparticles: Nanoparticles (NPs) are particles in the range of 1-100 nanometers $(\mathrm{nm})$ in size with a surrounding capping agent or otherwise known as stabilizer, surface ligand or passivating agent [17]. The capping agent is an integral part of nanoscale matter, fundamentally affecting all of NPs' properties, while it could be of various chemical compounds i.e. ions, inorganic and organic molecules endowing to the NP the appropriate surface chemistry endowing colloidal stability as well as proper surface functionalities for interaction with other substances. In nanotechnology, a particle is defined as a small object that behaves as a whole unit with respect to its transport and properties, while the type of NP element as a function of the size \& morphological characteristics could give a great variety of different properties (catalytic, sensing, electrical and thermal conductivity, bactericidal, etc.).
Figure 4 shows representatively scanning and transmission electron microscopy images (SEM, TEM images) of different NP types with different shapes; namely 1D, 2D and 3D NP geometries with different sizes and aspect ratio (length/ diameter). Figure 4 summarizes NPs i.e. multi-walled carbon nanotubes (MWCNTs) $[18,19]$ and Graphene monolayers (from the authors library of TEM images and materials' microscopy investigations), silica $\left(\mathrm{SiO}_{2}\right)$ [20], $\mathrm{Fe}_{3} \mathrm{O}_{4}$ superparamagnetic $\mathrm{NPs}$ and $\mathrm{Fe}_{3} \mathrm{O}_{4} @ \mathrm{SiO}_{2} @ \mathrm{Ag}$ core shell -satellite NPs [21], Au@Ag core-shell NPs [22], and polymeric spherical NPs loaded with pharmaceutical substances (carriers for drug delivery applications) deposited onto electros pinned nonwoven fabric biodegradable polymeric fibers (used as scaffolds for controlled drug release) [23].

Nanotechnology: Nanotechnology is considered as the technology that is focusing on the nanoscale and could find a great number of applications in the real world [24]. The exclusive physicochemical properties of nanomaterials can be utilized for applications that the whole scientific society could benefit i.e. electronics, biomedical devices, etc. applications. Nanotechnology could be regarded thus as a "megatrend" in the modern society and has become a "general purpose" technology.

Specifically, nanotechnology refers to the techniques manipulating the matter on an atomic, molecular, and supramolecular scale. With the use of nanotechnology, one could realize nano enabled macroscale products with engineered and 
precise control of the atoms and molecules position, orientation, etc. otherwise known as molecular nanotechnology [25]. The National Nanotechnology Initiative has given a more generalized description of nanotechnology defining "nanotechnology" as the manipulation of matter with at least one dimension sized from $1-100 \mathrm{~nm}$. Another definition states that nanotechnology is the design, characterization, production and application of structures, devices and systems by controlling shape and size at the nanometer scale [26]. It is now generally accepted that for a component or material to be considered as nano at least one critical dimension or manufacturing tolerances has to be below 100 nanometers, down to the size of atoms $(\sim 0.2 \mathrm{~nm})[27]$.
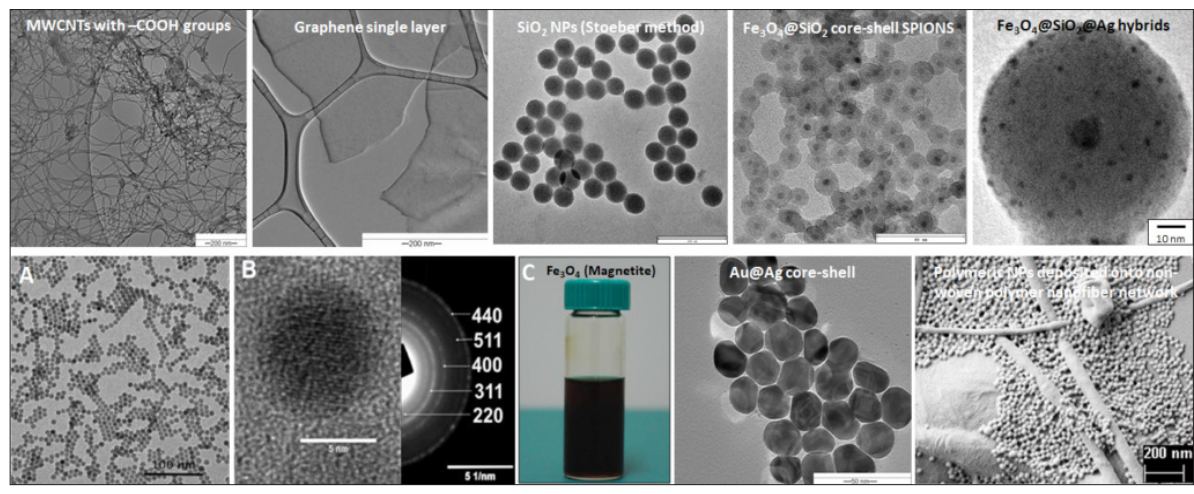

Figure 4: Representative SEM and TEM images of NP structures: Multi-walled carbon nanotubes (MWCNTs) and Graphene monolayers; silica (SiO2), Fe3O4 superparamagnetic NPs, Fe3O4@SiO2@Ag core shell -satellite NPs, Au@Ag core-shell NPs and polymeric NPs loaded with pharmaceutical substances (drug delivery) deposited onto electros pinned non-woven fabric biodegradable polymeric fibers (as scaffolds).

A huge number of new materials and devices that could find numerous applications as for instance in nanomedicine [28], nanoelectronics [29], energy production [30-32], and consumer products [33] could be realised making use of Nanotechnology methods and techniques. However, issues related to toxicity and the emerging environmental impacts that nanomaterials generate, as well as their potential effects on global economics are raised by the use of nanotechnology, related materials, and processes. These concerns have led to a dispute in the promotion groups and policy makers as well as the governments on whether special regulation of nanotechnology is necessary.

Namely, the revenues from nanotechnology derived products are growing on an annual basis exceeding for 2012 in the US the
$200 \mathrm{~B} \$$ in total, and over 700B $\$$ worldwide (over $1 \mathrm{~B} \$$ in 2018 and is projected to reach $\$ 2,231.4$ million by 2025 , growing at a CAGR of $10.5 \%$ from 2019 to 2025 - www.alliedmarketresearch. com/nanotechnologymarket\#: : text $=$ The $\% 20$ global $\% 20$ nanotechnology $\% 20$ market $\% 20$ was, $10.5 \% 25 \% 20$ from $\% 20$ $2019 \% 20$ to $\% 202025$.). This can give a direct image for the potential of the field with an impressive plausible return on investment under the successful market penetration [34]. At the same time, due to the variety of potential applications, globally billions of dollars have been invested in nanotechnology research. Namely, in 2012 USA invested 3.7B \$, Europe 2.1B \$ and Japan 750M\$.

Figure 5 illustrates everyday examples of things that fall in the macro- to nano- size range.

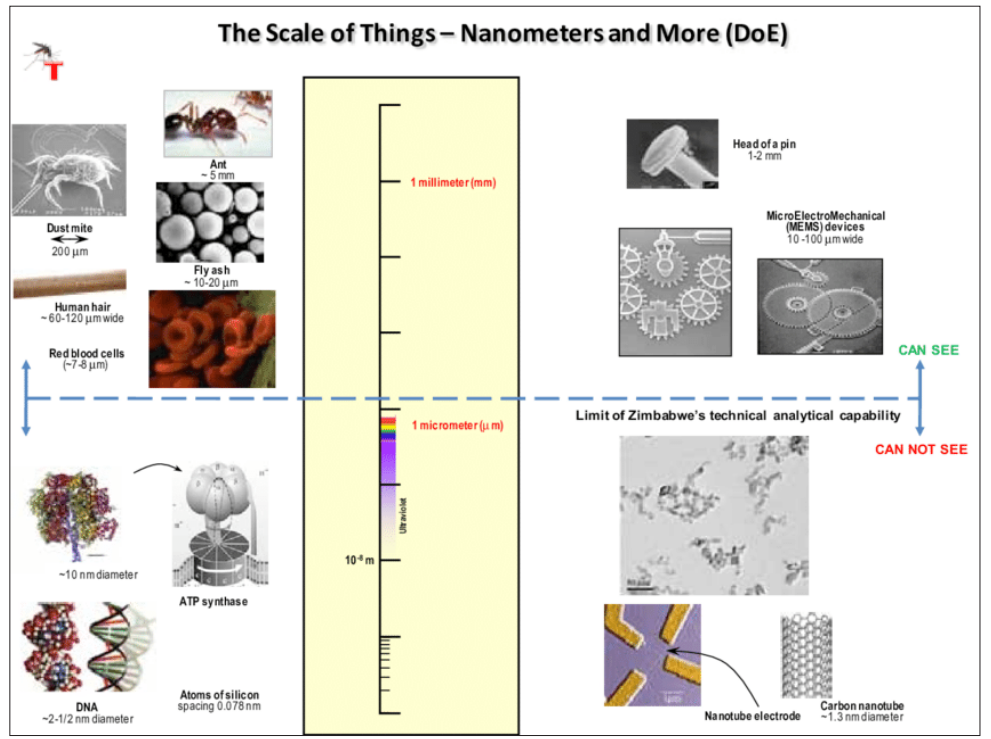

Figure 5: Scale of things from macro to nano size. The figure is courtesy of the DoE, 2006 [27]. 

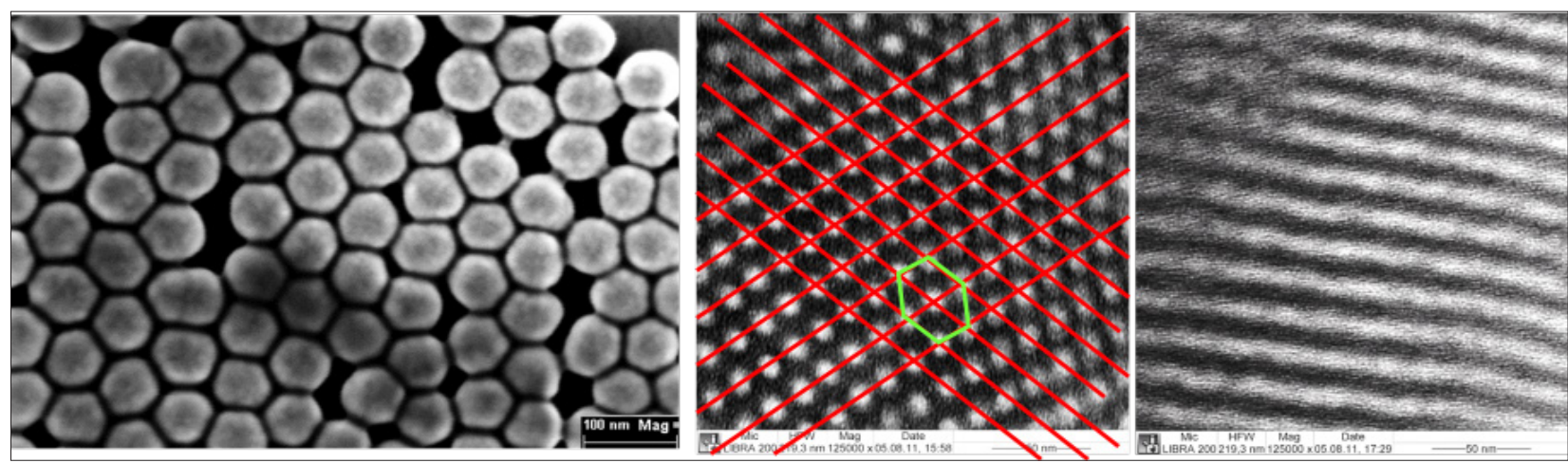

Figure 6: $\mathrm{SiO} 2$ spherical NPs that can self-assemble into hexagonally packed structures (left hand-side SEM image); and a block copolymer (BCP) with spherical morphology in which spheres are arranged into an hexagonally packed structure (middle TEM image); a block copolymer with lamellar morphology that lamellae have been oriented/ aligned using a shear force field (right hand-side TEM image).

Figure 6 illustrates some nano enabled structures that form well-ordered domains. Namely, a SEM image is depicted of $\mathrm{SiO}_{2}$ spherical NPs that can self-assemble into hexagonally packed structures (left hand-side) [20]; and TEM images of a block copolymer (BCP) with spherical morphology in which spheres are arranged into an hexagonally packed structure (middle image) [35], and finally a block copolymer with lamellar morphology that the lamellae have been oriented/ aligned using a shear force field with potential nanoelectronics, thin-film nanotemplates with anisotropic magnetic, electrical properties, etc. applications [36,37].

\section{Three-dimensional printing of thermoplastic nanocomposite materials through FFF towards multi- functional 3D printed objects}

Additive Manufacturing (AM) has been considered one of the most promising technologies the last decades and has found several applications in various scientific fields i.e. automotive, marine, electronics, biomedical, aerospace, etc. since it offers the ability to create functional $2 \mathrm{D}$ and $3 \mathrm{D}$ objects using a wide range of materials [38]. Especially, in several cases where state-of-the art technologies cannot overcome existing limitations i.e. in the medical field where customized parts are on demand on a daily use and the personalized medicine is of paramount importance, 2D and 3D printing are providing significant improvements in terms of design flexibility, fast production, availability, etc. [39]. Introducing nanomaterials could endow multifunctionality to the 2D and/ or 3D printed parts and objects with tailored and by-design properties i.e. increased strength and reduced weight, isotropic and anisotropic thermal and electrical conductivity, photonic emissions tunable for wavelength, etc.

Among AM techniques, Fused Filament Fabrication (FFF) uses as feedstock thermoplastics which then are extruded onto a build platform [40]. To enhance the properties of the polymeric matrices, particle reinforcements are widely used due to their low cost and the ease to be dispersed into the polymeric matrix via different versatile currently available technologies [41-43]. According to their type, size, geometry, aspect ratio, surface chemistry, etc. they have the potential to enhance different properties of the final composite and add new functionalities.

For instance, the addition of iron or copper particles to ABS can contribute to thermal conductivity and the improvement of the storage modulus, while it reduces the thermal expansion coefficient. An $\mathrm{Al}$ or $\mathrm{Al}_{2} \mathrm{O}_{3} /$ Nylon- 6 composite exhibits reduced frictional coefficient. $\mathrm{BaTiO}_{3}$ in $\mathrm{ABS}$ or $\mathrm{CaTiO}_{3}$ in polypropylene dispersion can offer enhanced dielectric permittivity and controllable resonance frequency. MWCNTs and their surface functional groups affect the thermoelectric properties of melt-mixed polycarbonate (PC) nanocomposites [44]. Apart from the traditional particles, numerus nanomaterials can offer exceptional mechanical, thermal and electrical properties to the polymeric matrix [45].

The addition of several nanomaterials for the production of composite parts utilizing 3D printing is also capable to increase the tensile strength [46]. For example, composite parts with $5 \mathrm{wt} \%$ titanium dioxide $\left(\mathrm{TiO}_{2}\right), 10 \mathrm{wt} \%$ carbon nanofibers or $10 \mathrm{wt} \%$ multi-walled carbon nanotubes exhibited an improvement of the tensile strength by $13.2 \%, 39 \%$ and $7.5 \%$ in comparison with neat polymer parts, respectively [47].

In another study, 3D printed nano- and micro-composites using ZnO nano- and micro-sized particles in Acrylonitrile Butadiene Styrene (ABS) matrix have shown a mechanical reinforcement effect on the 3D printed nanocomposite samples compared to that of the neat polymeric ABS matrix. Namely, compared to neat ABS the tensile strength was increased by $14 \%$ at $5 \%$ wt. concentration in both nanocomposite and micro-composite materials. Moreover, a $15.3 \%$ increase in the flexural strength was found in $0.5 \%$ wt. $\mathrm{ABS} / \mathrm{ZnO} 3 \mathrm{D}$ printed nanocomposite, while an increase of $17 \%$ was found for the $5 \% \mathrm{wt}$. ABS/ZnO micro-composite [48].

Two types of nano additives were employed in another reported article: namely (a) graphene nanoplatelets (GnP) at different concentrations, and (b) carbon nanotubes (CNTs), while FFF process was adopted to fabricate nanocomposite specimens 
that have been investigated in terms of mechanical performance and electrical conductivity [49]. The tensile as well as flexural properties (strength and modulus) showed a decreasing trend with the increase of the GnP loading. However, the ABS/CNT 3D printed nanocomposites showed higher tensile and flexural strength when compared to pure ABS and ABS with GnP. Moreover, electrical characterization of the 3D printed nanocomposites by DC methods and $\mathrm{AC}$ dielectric spectroscopy revealed that the dielectric constant increases with the higher GnP filler loading, while the specimens remained nonconductive, even when the GnP filler concentration was at the maximum that was able to be processed (10wt.\%). On the contrary, ABS/CNT nanocomposite with 10wt.\% filler loading exhibited a large electrical conductivity.

Tzounis et al. [50] recently reported on 3D Printed Thermoelectric Polyurethane (TPU)/Multiwalled Carbon Nanotube Nanocomposites [50]. 3D printing of stretchable, electrically, and thermoelectrically active polymer nanocomposite materials has been for the first time reported making use of flexible, stretchable and electrically conductive 3D printable thermoplastic polyurethane (TPU)/multiwalled carbon nanotube (MWCNT) filaments at various MWCNT filler loading. Advanced microscopy (SEM, TEM) showed the excellent achieved CNT nano dispersion in the TPU polymeric matrix due to the applied optimum melt mixing/ compounding and extrusion process parameters chosen. No remarkable knock-down effect was observed for the static tensile mechanical properties i.e. moduli and strengths, for the 3D printed samples compared to the nanocomposites prepared by compression molding. This indicates the high quality of adhesion for the 3D printed sample interlayers, translated into exceptional mechanical performance of the 3D printed nanocomposites achieved also by the optimum set of 3D printing parameters chosen. Thorough electrical and thermoelectric characterization illustrated that TPU/MWCNT conductive polymer composites (CPCs) at $5.0 \mathrm{wt} . \%$ exhibited the highest thermoelectric performance $(\sigma=133.1 \mathrm{~S} / \mathrm{m}$, $\mathrm{S}=19.8 \pm 0.2 \mu \mathrm{V} / \mathrm{K}$ and $\mathrm{PF}=0.04 \mu \mathrm{W} / \mathrm{mK}^{2}$ ) amongst TPU/CNT CPCs that can be found in literature. Finally, a very interesting feature the authors pointed out is an anisotropic electrical conductivity in the through- and cross-layer printing directions; however, the Seebeck coefficient remains the same.

Vairis et al. [51] reported on a very interesting study of the strain rate sensitivity of 3D printed ABS parts [51]. ABS samples 3D printed with dimensions according to ASTM D638-02a were tested at three different test speeds, namely as described by the ASTM D638-02a standard, lower, and higher as compared to the standard. The tensile strength values obtained were compared and discussed in relation to the investigated scanning electron microscope fracture surface images of selected specimens indicating the failure mode/ mechanism of the filament strands. The main finding has been that upon increasing the test strain rate, specimens develop higher tensile strength and Young's modulus. Specifically, specimens tested under the maximum speed of the experiment exhibited on average $\sim 11 \%$ higher tensile strength and $\sim 10 \%$ higher elastic modulus.
Just recently, the compressive behavior of an ABS FFF printed Steward Platform part has been reported [52]. In specific, ABS parts were $3 \mathrm{D}$ printed with variable printing parameters and investigated for their mechanical performance according to the ASTM D695 standard. Compression strength results were compared to stock ABS material values. A Steward Platform part was tested in compression mode, while a finite element model (FEM) of the Steward Platform part utilizing the experimental results was developed in order to determine the maximum force the part can withstand. The FEM results fully corroborated the experimental values measured in the Steward Platform part by the corresponding compressive tests. Moreover, another interesting finding has been the fact that with increasing the layer thickness, the ABS part showed lower compressive strength.

The mechanical properties of FFF manufactured specimens made of polylactic acid (PLA) and PLA nanocomposite with graphene nanoplatelets fillers (PLA/ GnP) has been experimentally measured [53]. Evaluation of the mechanical strength between FDM-printed PLA and PLA/GnP nanocomposites was performed to illustrate the filler's contribution. Moreover, the effect of the FFF printing process on the 3D printed samples' mechanical properties was elucidated by comparing them with the mechanical properties of the bulk injection molded specimens. The comparison demonstrated slight differences in the mechanical performance between the PLA/GnP nanocomposites prepared by FFF 3D printing and injection molding demonstrating that the mechanical performance is dominated by the PLA and the PLA/ GnP "material's" properties and not affected by the manufacturing process used to create 3D samples. Dielectric spectroscopy measurements were carried out to show the effect of GnP fillers in the dielectric properties of the material indicating a significant enhancement in the dielectric values.

Petousis et al. [54] have recently published on 3D printed antimicrobial thermoplastic nanocomposites [54]. In specific PLA/ AgNP nanocomposite filaments were produced initially by an insitu reduction reactive melt mixing process extruded further into nanocomposite filaments that were used for 3D printing. Silver nitrate (AgNO3) as precursor in powder form was mixed in the polymer melt and it has been reduced from silver ions (Ag+) into elemental (Ag0) nanoparticles utilizing polyethylene glycol (PEG) or polyvinyl pyrrolidone (PVP), as macromolecular reducing agents additives in the polymer melt. 3D printed antimicrobial (AM) PLA/AgNP parts were manufactured by Fused Filament Fabrication (FFF) and an optimum set of 3D printing parameters resulting in high quality $3 \mathrm{D}$ printed models and dog-bone samples used for mechanical tests. The 3D printed PLA/AgNP samples showed remarkable AM properties against Staphylococcus aureus (S. aureus) and Escherichia coli (E. coli) investigated by bacteria viability (\%) experiments. The 3D printed antimicrobial objects/ parts reported in this study could generate the seeds for further development of the recipe and the whole experimental protocol towards the next generation of nosocomial personal protective equipment (PPE), as well as biomedical antimicrobial equipment 
i.e. surgery equipment, implants, etc. It could be envisaged that such approaches could allow the low-cost, on demand and fast production of biomedical objects manufactured within the hospital endowing a personalized medicine character and capable to offer solutions in critical periods of the health systems as e.g. massive disasters, pandemics, etc.

Apart from the mechanical enhancement, the addition of nanoparticles in the polymeric matrix can contribute to the improvement of electrical and thermal properties. Gnanasekaran et al. [55] applied 3D printing of CNT- and graphene-based conductive polymer nanocomposites by FFF [55]. Authors used dispersions of CNTs and graphene (G) in polybutylene terephthalate (PBT). The results showed that electrical conductivity increased from $1 \times 10^{-13} \mathrm{~S} / \mathrm{m}$ for neat PBT to $11 \times 10^{1} \mathrm{~S} / \mathrm{m}$ for $3 \mathrm{D}$ printed polymer nanocomposites with CNTs and $1 \mathrm{~S} / \mathrm{m}$ with dispersed graphene. Additionally, they assessed thermal stability by conducting Thermogravimetric Analysis (TGA). They presented that the addition of conductive fillers enhanced the thermal stability, as both the maximum degradation temperature and the onset of the degradation mechanism shifted to a higher value. More specifically, a weight loss of $5 \%$ occurred at $303^{\circ} \mathrm{C}, 339^{\circ} \mathrm{C}$, and $332^{\circ} \mathrm{C}$ for the PBT, $\mathrm{PBT} / \mathrm{CNT}$ and $\mathrm{PBT} / \mathrm{G}$ respectively. Inlet guide van was fabricated from Glenn Research Center by using FFF process with Ultem 100 and chopped carbon fiber (CF) with operating temperature reaching $400{ }^{\circ} \mathrm{F}$. Carbon fibre reinforced Polyether Ether Ketone (PEEK) composites with 50\% less weight than aluminium was fabricated by Impossible Objects company, with heat resistance at about $250^{\circ} \mathrm{C}$, while maintaining $2 / 3$ rds of the aluminium's strength [47]. This composite material has been printed as demonstrator airfoil, rotor support arm and air intake (Figure 7).

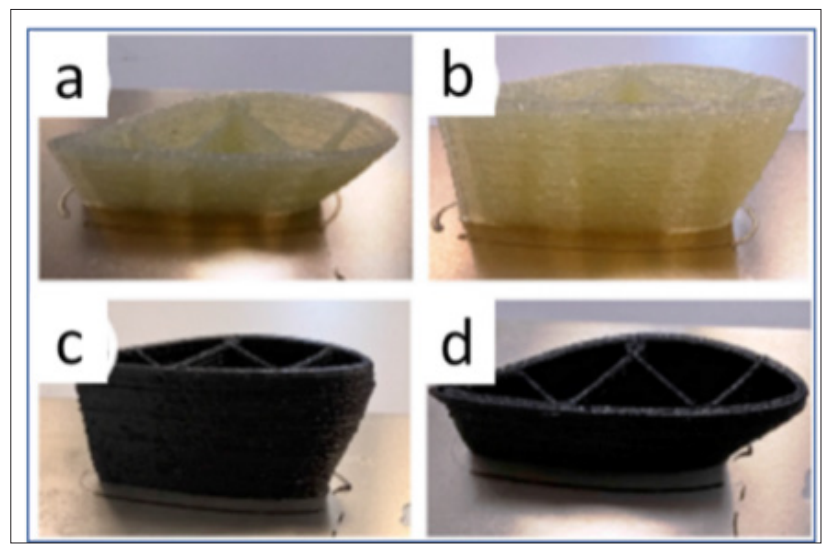

Figure 7: 3D printed airfoil demonstrators based on the glass fibre $(a, b)$ and carbon fibre $(c, d)$ formulations.

The specific and closely linked dependencies of production processes, materials and component design represent a challenge. The method of layer-wise construction enables the direct production of complex three-dimensional geometries in a single production step and without time-consuming process and tool planning. The higher the geometric complexity of the component, the greater the advantages of additives over conventional manufacturing. The above-mentioned properties open up new possibilities for structural optimization, especially in light-weight construction (Figure 8). Nearly any structure can be produced which has an adaptation of the design depending on the load situation and the stress distribution. In this context, with the increasing possibilities of additive manufacturing, research has focused in particular on cellular lightweight grid structures in combination with sandwich construction. This concept is based on the principle of inserting material only at places where it is required for force transmission or from an electromagnetic point of view [56]. Thereby, parts of the object with high material concentration are replaced by complex cellular structures [57]. The production of such structures is difficult or impossible with conventional methods, so that only the additive procedures make an economic conversion of such concepts possible.

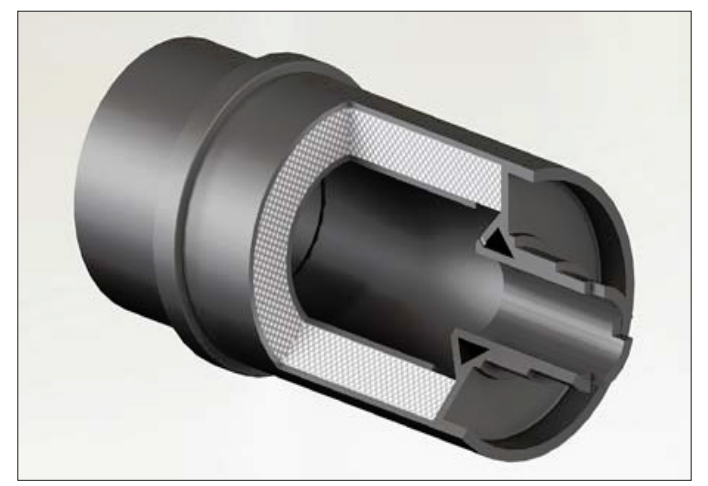

Figure 8: Optimized H13 rotor shaft with lattice structures for lightweight design optimization.

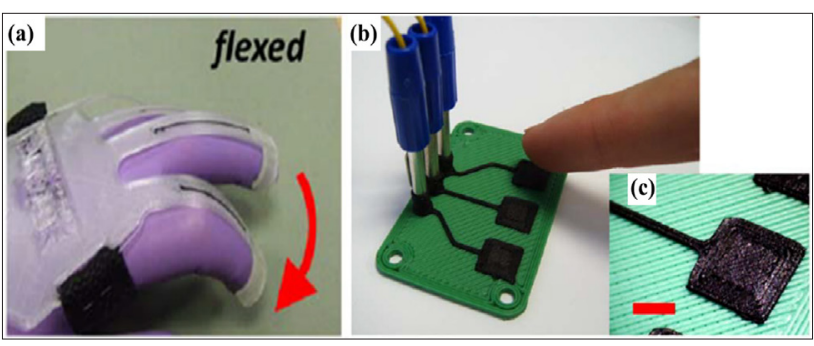

Figure 9: 3D printed carbon black/PCL composite for (a) Piezoresistive sensors (b) Capacitive sensors (c) macro image of the printed sensor pads (scale bar $5 \mathrm{~mm})$.

Christ et al. [58] fabricated FFF 3D printed nanocomposites of polyurethane/multiwalled carbon nanotube (TPU/MWCNT) with various MWCNT content up to 5 wt\% [58]. The results showed that the material strength, initial elastic modulus, and electrical conductivity enhanced with the increased addition of MWCNT filler. Also, different MWCNT contents can provide different ranges of flexibility and sensitivity, offering tunable properties for particular applications. TPU/MWCNT 3D printed nanocomposites can also be 
used as excellent piezoresistive feedstock for strain sensors. Other potential applications are in the fields of wearable electronics, soft robotics, and prosthetics (Figure 9). Chizari et al. [59], developed highly conductive nanocomposite materials (up to $5000 \mathrm{Sm}^{-1}$ ) for SC-3D printing of 2D and 3D structures with applications in liquid sensing and EMI shielding [59].

3D printing of thermoplastic nanocomposites towards biomedical applications: Recent trends and challenges: 3D printing FFF method could allow direct printing of nanomaterialsmodified filaments, to bring a new paradigm for nanocomposite functionality in bulk 3D objects [60]. A novel development accomplished with 3D printing process was a formatting glove with embedded programmable heater, temperature sensors and the ability of thermotherapeutic treatment via associated control electronics [61].

Palmiga company (Palmiga Sweden; https://palmiga.com/) developed and characterized polymer based conductive 3D-printed EMG sensors/ electrodes (EMG: electromyography). In comparison to the gold standard $\mathrm{Ag} / \mathrm{AgCl}$ gel electrodes, there was no remarkable difference in the EMG signal amplitude under the same conduct area. The sensors were capable to distinguish a big number of muscle activity of the biceps brachii. The experimental data and signals acquired gives 3D printed EMG electrodes a big opportunity to replace the state-of-the art electrode wearable technologies towards personalized sensing elements and structures, e.g. in prosthetic and orthotic contexts [62] (Figure 10).

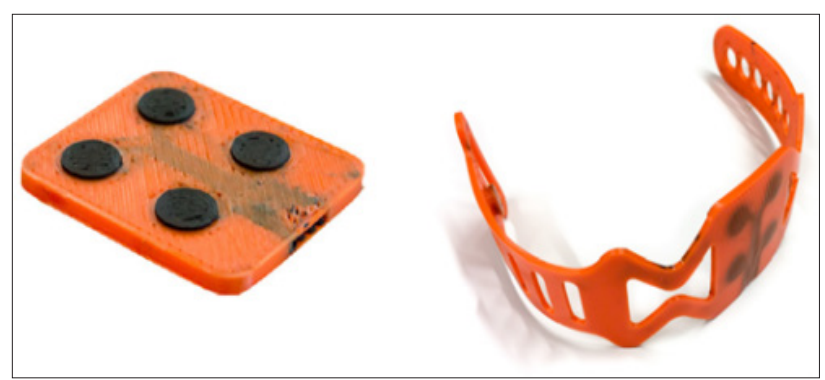

Figure 10: Photograph of 3D-Printed EMG electrodes using flexible conductive filaments (TPU/ Carbon black based).

Palmiga also constructed a flexible force sensor by 3D printed conductive Thermoplastic Polyurethane (TPU). The capacitance of the sensor changed due to an applied sinusoidal force. The experiments were carried out utilising a readout circuit and an oscillatory set-up consisting of an operational amplifier and a frequency-counter based on an Arduino Nano. From this study, the possibility to implement low-cost capacitive sensors into 3D printed objects has been elaborated, which could be of interest for customized robotic and prosthetic applications [63].

Discussion and future perspectives: Advancements beyond the state-of-the-art: Additive manufacturing and especially FFF 3D printing have been investigated for surgical implants, tissue scaffolds, and organs [64]. Till now, the most important application of 3D printing in the medical field is the design and development of medical devices and instrumentation $[65,66]$. One high impact example of 3D printing in the biomedical sector is the use of patient specific computed tomography derived 3D prints for better preoperative planning to better organize surgical approaches [67], plan complex operations [68-70] and/or for surgical educational proposes [71]. Moreover, 3D models of patient-specific anatomy, such as dental crowns and biological scaffolds are already being used for human implants [72-74].

With regard to bio-related applications, PLA and Polyglycolic Acids are very promising and widely used materials that have been already investigated for biodegradable implants and suture material, such as Vicryl (Ethicon, New Brunswick, NJ) [73]. PLA has been found after cytotoxicity experiments to be safe for surgical implantation as it is a biocompatible and biodegradable polymeric material. As such, PLA could be used for 3D printing a great variety of biomedical objects i.e. surgical instruments, sutures, surgical grids, etc.

Surgery equipment should have the ability to be sterilized as it is of paramount to its application, while possible being sterilized for several times making the objects reusable till their end-of-life. PLA is normally extruded at temperatures $>150{ }^{\circ} \mathrm{C}$ rendering possible its exposure and application for steam sterilization or even for dry heat sterilization at $170{ }^{\circ} \mathrm{C}$ [74]. However, lower temperature methods of sterilization such as ethylene oxide "gas" sterilization did not impact PLA strength. Alternatively, an effective sterilant for room temperature treatment; glutaraldehyde, has been shown to retain the greatest PLA strength, when compared with other chemical sterilants [75].

The main characteristics that a surgery instrument should exhibit is to be sterile before use, as well as to possibly have the durability of several cycles of typical sterilization process treatments in the routine applied methods in the daily use of the nosocomial application. Moreover, it would be very beneficial surgery instrument to exhibit anti-adhesive properties as well as potentially resistance to biofilm formation i.e. antibacterial properties against specific bacteria strains upon being in contact, etc. This is because surgery that involves a cut (incision) in the skin can lead to a wound infection after surgery.

Therefore, an important issue in 3D printed biomedical objects is to endow antimicrobial properties to the final object. For this purpose, polymeric materials are ideal candidates since they can be modified by incorporating antimicrobial agents in their bulk structure e.g. by solvent of melt-mixing; or by depositing thin AM films onto their surface resulting into the desired properties. Various antimicrobial agents have been extensively investigated and the results showed that there is a great potential that can be utilized in order to prevent the growth of pathogenic microorganisms, as for instance bacteria, fungi, algae, etc. [7678]. Namely, polyhexamethylene biguanides, triclosan biopolymer, chitosan, quaternary ammonium compounds, N-halamine, Silver and copper metal salts and complex molecules as well as $\mathrm{Ag}$ and $\mathrm{Cu}$ 
nanoparticles (NPs), etc. are some of the AM agents that could be introduced in a polymer matrix or being deposited as thin films on polymeric material surfaces [79].

Silver has been one of the most used materials as antibacterial agent among the above mentioned ones in the form of NPs, complexes and salt, due to its wide spectrum of antibacterial activity combined with the experimentally proven low toxicity towards mammalian cells [80]. One of the most plausible mechanisms for the AgNPs' antimicrobial activity is the release of silver ions from the particle's surface. Silver in its ionized form is well-known that is highly active, since it binds to tissue proteins and brings structural changes to the bacterial cell wall and nuclear membrane leading thus to cell distortion and finally bacterial cell death [81]. Therefore, the small size of silver nanoparticles (Ag NPs) has rendered them a new class of antibacterial agents with exceptional properties for different medical applications [82].

Many approaches have been reported in literature with the aim to incorporate silver nanoparticles (AgNPs) in a polymer matrix or the deposition of thin films consisting of silver onto polymeric surfaces with engineering of the surface interaction and adhesion of the thin film deposited material with the underlying substrate. Solvent mixing is one possible technique to introduce AgNPs (or any other type of antibacterial NPs in a polymer matrix) in a polymer matrix as reported elsewhere [83]. Magnetron sputtering [84], ionbeam-assisted deposition process [85], dip-coating using colloidal silver [86] and sonochemistry depositions methods [87,88] have been reported for the deposition of AgNPs onto polymeric surfaces.

Surgical equipment like for instance an antimicrobial retractor could be fabricated by 3D printing the 3D object and subsequent deposition of a nano-layer of a specific antimicrobial agent. Especially in the health and hygienic field, a great focus is given to develop planar surfaces, bulk materials, textiles, etc. with antimicrobial properties. More specific, the 3D objects could be produced at a specific use-case and by design as well as patient specific. Since PLA has been proven to be biocompatible and biodegradable and a safe material even for surgical implantation, it can be selected for various future applications as it is a cost effective, safe, and environmentally suitable material for 3D printing.

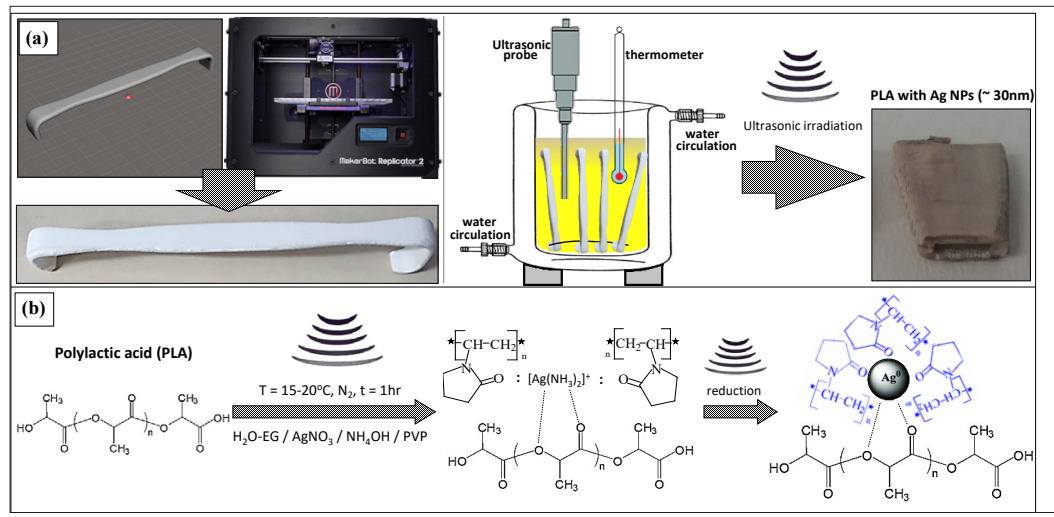

Figure 11: (a) Process for 3D printing a PLA surgical retractor, as well as the method for sonochemically immobilizing Ag NPs; (b) chemicals and the protocol followed to achieve high quality monodispersed Ag NPs immobilized onto the retractor surface.

Figure 11a shows the process for 3D printing a PLA surgical retractor, as well as the method for sonochemically immobilizing Ag NPs; while the chemicals and the protocol followed to achieve high quality monodispersed Ag NPs immobilized onto the retractor surface are illustrated in Figure 11b (recently published by Tzounis et al. [89])

The optimization of 3D FFF AM processes via on-line monitoring and modeling approaches have the potential to provide high-quality components with built-in functionalities for multiple applications in various fields such as Health, Automotive, Aeronautics \& Aerospace, Consumer goods \& Electronics, Industrial equipment \& Tooling, Construction and Energy. Additionally, 3D FFF AM further developments at process and process optimization and process monitoring control level, as well as at materials level will improve the reliability, the quality and the accuracy as well as the multimaterial capabilities through printed processes of nanocomposite filaments as fast as standard materials by avoiding process related issues $[90,91]$.

\section{Conclusion}

In this mini review article, an introduction to 2D and 3D AM processes as well as to nanotechnology and nanomaterials has been given, with a specific focus on combining the 3D printing with nano enabled materials towards "smart" and multifunctional nanotechnology-enabled 3D printed objects. Many examples of nano enabled 3D objects are described, and a special attention is given on biomedical objects and potential products, i.e. EMG sensors, surgery equipment, 3D printed gloves with embedded programmable heaters, temperature sensors for thermotherapeutic treatment, etc.

It is of utmost importance that scientists from different sectors will realize the mutual benefits of combining additive manufacturing (AM) technologies with nanomaterials and nanotechnology 
concepts. Even if the nanomaterials and nanotechnology are in quite early stages of being implemented into AM processes and technologies, it is true that there are several cases for the application in order to enhance some of the existing and endow new properties to 3D manufactured objects and products. All these needs further investigation to realize how the 3D printing process itself can be affected (i.e. destroy the printer heads, etc.) and the orienting parameters to be appropriately optimized and adjusted. In that respect, both nanomaterials can be tuned to allow their ease of processing by additive manufacturing technologies as well as the printing process and the printing machinery can be accordingly customized allowing the printing of nano enabled products. It is undoubtful that the nanotechnology and additive manufacturing communities as well as researchers active in these fields could benefit from increased academic and research interactions and collaborations. Only through such greater engagement, 3D printing of multifunctional nano-enabled objects could be realised.

\section{Acknowledgment}

L.T. gratefully acknowledges the Bodossaki Foundation for financial support in the framework of institutional scholarships.

\section{Conflicts of Interest}

The authors declare no conflict of interest. The funding sponsors had no role in the design of the study; in the collection, analyses, or interpretation of data; in the writing of the manuscript, and in the decision to publish the results.

\section{References}

1. Vaezi M, Seitz H, Yang S (2013) A review on 3D micro-additive manufacturing technologies. The International Journal of Advanced Manufacturing Technology 67(5): 1721-1754.

2. Takagishi K, Umezu S (2017) Development of the improving process for the 3D printed structure. Scientific Reports 7: 39852.

3. Lewicki JP, Rodriguez JN, Zhu C, Worsley MA, Wu AS, et al. (2017) 3D-Printing of meso-structurally ordered carbon fiber/polymer composites with unprecedented orthotropic physical properties. Scientific Reports 7: 43401.

4. Pitsalidis C, Ferro MP, Iandolo D, Tzounis L, Inal S, et al. (2018) Transistor in a tube: A route to three-dimensional bioelectronics. Science Advances 4(10): eaat 4253.

5. Tzounis L, Gravalidis C, Vassiliadou S, Logothetidis S (2017) Fiber yarns/ CNT hierarchical structures as thermoelectric generators. Materials Today: Proceedings 4(7, Part 1): 7070-7075.

6. Felisberto M, Tzounis L, Sacco L, Stamm M, Candal R, et al. (2017) Carbon nanotubes grown on carbon fiber yarns by a low temperature CVD method: A significant enhancement of the interfacial adhesion between carbon fiber/epoxy matrix hierarchical composites. Composites Communications 3: 33-37.

7. Kang H, Park H, Park Y, Jung M, Kim BC, et al. 92014) Fully roll-to-roll gravure printable wireless $(13.56 \mathrm{MHz})$ sensor-signage tags for smart packaging. Scientific Reports 4: 5387.

8. Kapnopoulos C, Mekeridis ED, Tzounis L, Polyzoidis C, Zachariadis A, et al. (2016) Fully gravure printed organic photovoltaic modules: A straightforward process with a high potential for large scale production. Solar Energy Materials and Solar Cells 144: 724-731.
9. Kapnopoulos C, Mekeridis ED, Tzounis L, Polyzoidis C, Tsimikli S, et al. (2016) Gravure printed organic photovoltaic modules onto flexible substrates consisting of a P3HT:PCBM photoactive Blend ${ }^{1}$. Materials Today: Proceedings 3(3): 746-757.

10. Tzounis L, Stergiopoulos T, Zachariadis A, Gravalidis C, Laskarakis A, et al. (2017) Perovskite solar cells from small scale spin coating process towards roll-to-roll printing: Optical and Morphological studies. Materials Today: Proceedings 4(4, Part B): 5082-5089.

11. Schmitt M, Baunach M, Wengeler L, Peters K, Junges P, et al. (2013) Processing of lithium-ion battery electrodes-Coating window characterization. Chemical Engineering and Processing: Process Intensification 68: 32-37.

12. Bariya M, Shahpar Z, Park H, Sun J, Jung Y, et al. (2018) Roll-to-roll gravure printed electrochemical sensors for wearable and medical devices. ACS Nano 12(7): 6978-6987.

13. Karim N, Afroj S, Malandraki A, Butterworth S, Beach C, et al. (2017) All inkjet-printed graphene-based conductive patterns for wearable e-textile applications. Journal of Materials Chemistry C 5(44): 1164011648.

14. Kellenberger CR, Hess SC, Schumacher CM, Loepfe M, Nussbaumer JE, et al. (2014) Roll-to-roll preparation of mesoporous membranes by nanoparticle template removal. Industrial \& Engineering Chemistry Research 53(22): 9214-9220.

15. Bangeas P, Drevelegas K, Agorastou C, Tzounis L, Chorti A, et al. (2019) Three-dimensional printing as an educational tool in colorectal surgery. Front Biosci (Elite Ed) 11: 29-37.

16. Rankin TM, Giovinco NA, Cucher DJ, Watts G, Hurwitz B, et al. (2014) Three-dimensional printing surgical instruments: are we there yet? Journal of Surgical Research 189(2): 193-197.

17. Tzounis L (2019) Chapter 9 - synthesis and processing of thermoelectric nanomaterials, nanocomposites, and devices. Nanomaterials Synthesis. In: Beeran Pottathara Y, Thomas S, Kalarikkal N, Grohens Y, Kokol V (Eds.), Elsevier, pp. 295-336.

18. Tzounis L, Zappalorto M, Panozzo F, Tsirka K, Maragoni L, et al. (2019) Highly conductive ultra-sensitive SWCNT-coated glass fiber reinforcements for laminate composites structural health monitoring. Composites Part B: Engineering 169: 37-44.

19. Tzounis L, Liebscher M, Fuge R, Leonhardt A, Mechtcherine V (2019) $\mathrm{P}$ - and n-type thermoelectric cement composites with CVD grown p- and n-doped carbon nanotubes: Demonstration of a structural thermoelectric generator. Energy and Buildings 191: 151-163.

20. Tzounis L, Contreras-Caceres R, Schellkopf L, Jehnichen D, Fischer D, et al. (2014) Controlled growth of Ag nanoparticles decorated onto the surface of $\mathrm{SiO}_{2}$ spheres: a nanohybrid system with combined SERS and catalytic properties. RSC Advances 4(34): 17846-17855.

21. Tzounis L, Logothetidis $\mathrm{S}$ (2017) $\mathrm{Fe}_{3} \mathrm{O}_{4} @ \mathrm{SiO}_{2}$ core shell particles as platforms for the decoration of $\mathrm{Ag}$ nanoparticles. Materials Today: Proceedings 4(7, Part 1): 7076-7082.

22. Contreras-Caceres R, Dawson C, Formanek P, Fischer D, Simon F, et al. (2013) Polymers as templates for Au and Au@Ag bimetallic nanorods: UV-Vis and surface enhanced raman spectroscopy. Chemistry of Materials 25(2): 158-169.

23. Pappa AM, Karagkiozaki V, Krol S, Kassavetis S, Konstantinou D, et al. (2015) Oxygen-plasma-modified biomimetic nanofibrous scaffolds for enhanced compatibility of cardiovascular implants. Beilstein Journal of Nanotechnology 6: 254-262.

24. Tzounis L, Kirsten M, Simon F, Mäder E, Stamm M (2014) The interphase microstructure and electrical properties of glass fibers covalently and non-covalently bonded with multiwall carbon nanotubes. Carbon 73: 310-324. 
25. Karalis G, Tzounis L, Lambrou E, Gergidis LN, Paipetis AS (2019) A carbon fiber thermoelectric generator integrated as a lamina within an 8-ply laminate epoxy composite: Efficient thermal energy harvesting by advanced structural materials. Applied Energy 253: 113512.

26. (2004) Nanoscience and nanotechnologies: Opportunities and uncertainties. Royal Society.

27. Malanowski N, Zweck A (2007) Bridging the gap between foresight and market research: Integrating methods to assess the economic potential of nanotechnology. Technological Forecasting and Social Change 74(9): 1805-1822.

28. Perli MD, Karagkiozaki V, Pappa F, Moutsios I, Tzounis L, et al. (2017) Synthesis and characterization of Ag nanoparticles for orthopaedic applications. Materials Today: Proceedings 4(7, Part 1): 6889-6900.

29. Borges BG, Veiga AG, Gioti M, Laskarakis A, Tzounis L, et al. (2018 Surface, interface and electronic properties of F8: F8BT polymeric thin films used for organic light-emitting diode applications. Polymer International 67(6): 691-699.

30. Papageridis KN, Siakavelas G, Charisiou ND, Avraam DG, Tzounis L, et al. (2016) Comparative study of $\mathrm{Ni}, \mathrm{Co}, \mathrm{Cu}$ supported on $\gamma$-alumina catalysts for hydrogen production via the glycerol steam reforming reaction. Fuel Processing Technology 152: 156-175.

31. Charisiou ND, Siakavelas G, Tzounis L, Sebastian V, Monzon A, et al. (2018) An in-depth investigation of deactivation through carbon formation during the biogas dry reforming reaction for $\mathrm{Ni}$ supported on modified with $\mathrm{CeO}_{2}$ and $\mathrm{La}_{2} \mathrm{O}_{3}$ zirconia catalysts. International Journal of Hydrogen Energy 43(41): 18955-18976.

32. Charisiou ND, Papageridis KN, Tzounis L, Sebastian V, Hinder SJ, et al. (2019) $\mathrm{Ni}$ supported on $\mathrm{CaO}-\mathrm{MgO}-\mathrm{Al}_{2} \mathrm{O}_{3}$ as a highly selective and stable catalyst for $\mathrm{H}_{2}$ production via the glycerol steam reforming reaction. International Journal of Hydrogen Energy 44(1): 256-273.

33. Wise K, Brasuel M (2011) The current state of engineered nanomaterials in consumer goods and waste streams: the need to develop nano property-quantifiable sensors for monitoring engineered nanomaterials. Nanotechnol Sci Appl 4: 73-86.

34. Bhushan B (2017) Introduction to nanotechnology. In Springer Handbook of Nanotechnology, Bhushan B (Ed.), Springer Berlin Heidelberg: Berlin, Heidelberg, Germany, pp. 1-19.

35. Carrasco PM, Tzounis L, Mompean FJ, Strati K, Georgopanos P, et al. (2013) Thermoset magnetic materials based on poly(ionic liquid)s block copolymers. Macromolecules 46(5): 1860-1867.

36. Wode F, Tzounis L, Kirsten M, Constantinou M, Georgopanos P, et al. (2012) Selective localization of multi-wall carbon nanotubes in homopolymer blends and a diblock copolymer. Rheological orientation studies of the final nanocomposites. Polymer 53(20): 4438-4447.

37. Tzounis L, Pegel S, Zafeiropoulos NE, Avgeropoulos A, Paipetis AS, et al. (2017) Shear alignment of a poly(styrene-butadiene-styrene) triblock copolymer/MWCNT nanocomposite. Polymer 131: 1-9.

38. Bangeas P, Tzounis L, Karolos I, Stavrides E, Paramythiotis D, et al. (2018) Evaluation of three-dimensional printed models in surgical education: a paradigm of a new educational method for the simulation of surgery environment. HPB 20: S779.

39. Malik HH, Darwood ARJ, Shaunak S, Kulatilake P, El-Hilly AA, et al. (2015) Three-dimensional printing in surgery: a review of current surgical applications. Journal of Surgical Research 199(2): 512-522.

40. Rodríguez José F (2003) Mechanical behavior of acrylonitrile butadiene styrene fused deposition materials modeling. Rapid Prototyping Journal 9(4): 219-230.

41. Tzounis L, Gärtner T, Liebscher $M$, Pötschke $P$, Stamm $M$, et al. (2014) Influence of a cyclic butylene terephthalate oligomer on the processability and thermoelectric properties of polycarbonate/MWCNT nanocomposites. Polymer 55(21): 5381-5388.

42. Papageorgiou DG, Tzounis L, Papageorgiou GZ, Bikiaris DN, Chrissafis K (2014) $\beta$-nucleated propylene-ethylene random copolymer filled with multi-walled carbon nanotubes: Mechanical, thermal and rheological properties. Polymer 55(16): 3758-3769.

43. Tzounis L, Hegde M, Liebscher M, Dingemans T, Pötschke P, et al. (2018) All-aromatic SWCNT-Polyetherimide nanocomposites for thermal energy harvesting applications. Composites Science and Technology 156: 158-165.

44. Liebscher M, Gärtner T, Tzounis L, Mičušík M, Pötschke P, et al. (2014) Influence of the MWCNT surface functionalization on the thermoelectric properties of melt-mixed polycarbonate composites. Composites Science and Technology 101: 133-138.

45. Terzopoulou Z, Patsiaoura D, Papageorgiou DG, Pavlidou E, Chrissafis K, et al. (2017) Effect of MWCNTs and their modification on crystallization and thermal degradation of poly(butylene naphthalate). Thermochimica Acta 656: 59-69.

46. Liebscher M, Tzounis L, Pötschke P, Heinrich G (2013) Influence of the viscosity ratio in PC/SAN blends filled with MWCNTs on the morphological, electrical, and melt rheological properties. Polymer 54(25): 6801-6808.

47. Wang X, Jiang M, Zhou Z, Gou J, Hui D (2017) 3D printing of polymer matrix composites: A review and prospective. Composites Part B: Engineering 110: 442-458.

48. Vidakis N, Petousis M, Maniadi A, Koudoumas E, Kenanakis G, et al. (2020) The mechanical and physical properties of 3D-printed materials composed of ABS-ZnO nanocomposites and ABS-ZnO microcomposites. Micromachines 11(6).

49. Vidakis N, Maniadi A, Petousis M, Vamvakaki M, Kenanakis G, et al. (2020) Mechanical and electrical properties investigation of 3D-printed acrylonitrile-butadiene-styrene graphene and carbon nanocomposites. Journal of Materials Engineering and Performance 29(3): 1909-1918.

50. Tzounis L, Petousis M, Grammatikos S, Vidakis N (2020) 3D printed thermoelectric polyurethane/multiwalled carbon nanotube nanocomposites: A novel approach towards the fabrication of flexible and stretchable organic thermoelectric. Materials 13(12): 2879.

51. Vairis A, Petousis M, Vidakis N, Savvakis K (2016) On the strain rate sensitivity of abs and abs plus fused deposition modeling parts. Journal of Materials Engineering and Performance 25(9): 3558-3565.

52. Vidakis N, Petousis M, Vairis A, Savvakis K, Maniadi A (2017) On the compressive behavior of an FDM steward platform part. Journal of Computational Design and Engineering 4(4): 339-346.

53. Vidakis N, Petousis M, Savvakis K, Maniadi A, Koudoumas E (2019) A comprehensive investigation of the mechanical behavior and the dielectrics of pure polylactic acid (PLA) and PLA with graphene (GnP) in fused deposition modeling (FDM). International Journal of Plastics Technology 23(2): 195-206.

54. Vidakis N, Petousis M, Velidakis E, Liebscher M, Tzounis L (2010) Threedimensional printed antimicrobial objects of Polylactic Acid (PLA)-silver nanoparticle nanocomposite filaments produced by an in-situ reduction reactive melt mixing process. Biomimetics 5(3): 42 .

55. Gnanasekaran K, Heijmans T, van Bennekom S, Woldhuis H, Wijnia S, et al. (2017) 3D printing of CNT- and graphene-based conductive polymer nanocomposites by fused deposition modeling. Applied Materials Today 9: 21-28.

56. Krenkel W (2009) Composites: $17^{\text {th }}$ symposium on composites and composites. Wiley.

57. Lock C, Reinhart G (2016) A meta-model for analyzing the influence of production-related business processes. Procedia 57: 79-84. 
58. Christ JF, Aliheidari N, Ameli A, Pötschke P (2017) 3D printed highly elastic strain sensors of multiwalled carbon nanotube/thermoplastic polyurethane nanocomposites. Materials \& Design 131: 394-401.

59. Chizari K, Arjmand M, Liu Z, Sundararaj U, Therriault D (2017) Threedimensional printing of highly conductive polymer nanocomposites for EMI shielding applications. Materials Today Communications 11: 112118.

60. Campbell TA, Ivanova OS (2013) 3D printing of multifunctional nanocomposites. Nano Today 8(2): 119-120.

61. Ota H, Emaminejad S, Gao Y, Zhao A, Wu E, et al. (2016) Application of 3D printing for smart objects with embedded electronic sensors and systems. Advanced Materials Technologies 1(1): 1600013.

62. Wolterink G, Sanders R, Muijzer F, Beijnum B (2017) In 3D-printing soft sEMG sensing structures, 2017 IEEE SENSORS. Pp. 1-3.

63. Schouten M, Sanders R, Krijnen G (2017) In 3D printed flexible capacitive force sensor with a simple micro-controller-based readout, 2017 IEEE SENSORS. pp. 1-3.

64. Nguyen D, Hägg DA, Forsman A, Ekholm J, Nimkingratana P, et al. (2017) Cartilage tissue engineering by the 3D bioprinting of iPS cells in a nanocellulose/alginate bioink. Scientific Reports 7(1): 658.

65. Sodian R, Schmauss D, Schmitz C, Bigdeli A, Haeberle S, et al. (2009) 3-Dimensional printing of models to create custom-made devices for coil embolization of an anastomotic leak after aortic arch replacement. The Annals of Thoracic Surgery 88(3): 974-978.

66. Kurenov SN, Ionita C, Sammons D, Demmy TL (2015) Three-dimensional printing to facilitate anatomic study, device development, simulation, and planning in thoracic surgery. The Journal of Thoracic and Cardiovascular Surgery 149(4): 973-979.e1.

67. Bangeas P, Voulalas G, Ktenidis K (2016) Rapid prototyping in aortic surgery. Interactive Cardio Vascular and Thoracic Surgery 22(4): 513514.

68. Sodian R, Schmauss D, Markert M, Weber S, Nikolaou K, et al. (2008) Three-dimensional printing creates models for surgical planning of aortic valve replacement after previous coronary bypass grafting. The Annals of Thoracic Surgery 85(6): 2105-2108.

69. Kolyva C, Biglino G, Pepper JR, Khir AW (2012) A mock circulatory system with physiological distribution of terminal resistance and compliance: application for testing the intra-aortic balloon pump. Artif Organs 36(3): E62-70.

70. Biglino G, Capelli C, Binazzi A, Reggiani R, Cosentino D, et al. (2012) Virtual and real bench testing of a new percutaneous valve device: a case study. EuroIntervention 8(1): 120-128.

71. Lioufas PA, Quayle MR, Leong JC, McMenamin PG (2016) 3D printed models of cleft palate pathology for surgical education. Plastic and reconstructive surgery. Global open 4(9): e1029.

72. Michael S, Sorg H, Peck CT, Koch L, Deiwick A, et al. (2013) Tissue engineered skin substitutes created by laser-assisted bioprinting form skin-like structures in the dorsal skin fold chamber in mice. PLOS ONE 8(3): e57741.

73. Meseguer-Olmo L, Vicente-Ortega V, Alcaraz-Baños M, Calvo-Guirado JL, Vallet-Regí M, et al. (2013) In-vivo behavior of Si-hydroxyapatite/ polycaprolactone/DMB scaffolds fabricated by 3D printing. Journal of Biomedical Materials Research Part A 101A(7): 2038-2048.

74. Fedorovich NE, Alblas J, Hennink WE, Öner FC, Dhert WJA (2011) Organ printing: the future of bone regeneration? Trends in Biotechnology 29(12): 601-606.
75. Athanasiou KA, Niederauer GG, Agrawal CM (1996) Sterilization, toxicity, biocompatibility and clinical applications of polylactic acid/ polyglycolic acid copolymers. Biomaterials 17(2): 93-102.

76. Gorenšek M, Gorjanc M, Bukošek V, Kovač J, Petrović Z, et al. (2010) Functionalization of polyester fabric by $\mathrm{Ar} / \mathrm{N}_{2}$ plasma and silver. Textile Research Journal 80(16): 1633-1642.

77. Cheng X, Ma K, Li R, Ren X, Huang TS (2014) Antimicrobial coating of modified chitosan onto cotton fabrics. Applied Surface Science 309: 138143.

78. Shahid ul I, Shahid M, Mohammad F (2013) Green chemistry approaches to develop antimicrobial textiles based on sustainable biopolymers-A review. Industrial \& Engineering Chemistry Research 52(15): 52455260 .

79. Deng X, Yu Nikiforov A, Coenye T, Cools P, Aziz G, et al. (2015) Antimicrobial nano-silver non-woven polyethylene terephthalate fabric via an atmospheric pressure plasma deposition process. Scientific Reports 5: 10138.

80. Shrivastava S, Bera T, Singh SK, Singh G, Ramachandrarao P, et al. (2009) Characterization of antiplatelet properties of silver nanoparticles. ACS Nano 3(6): 1357-1364

81. Feng QL, Wu J, Chen GQ, Cui FZ, Kim TN, et al. (2000) A mechanistic study of the antibacterial effect of silver ions on Escherichia coli and Staphylococcus aureus. Journal of Biomedical Materials Research 52(4): 662-668.

82. Chaloupka K, Malam Y, Seifalian AM (2010) Nanosilver as a new generation of nanoproduct in biomedical applications. Trends in Biotechnology 28(11): 580-588.

83. Sawant SN, Selvaraj V, Prabhawathi V, Doble M (2013) Antibiofilm properties of silver and gold incorporated PU, PCLm, PC and PMMA nanocomposites under two shear conditions. PLOS ONE 8(5): e63311.

84. Chen YH, Hsu CC, He JL (2013) Antibacterial silver coating on poly(ethylene terephthalate) fabric by using high power impulse magnetron sputtering. Surface and Coatings Technology 232: 868-875.

85. Jiang SX, Qin WF, Guo RH, Zhang L (2010) Surface functionalization of nanostructured silver-coated polyester fabric by magnetron sputtering. Surface and Coatings Technology 204(21-22): 3662-3667.

86. Jeong SH, Hwang YH, Yi SC (2005) Antibacterial properties of padded $\mathrm{PP} / \mathrm{PE}$ nonwovens incorporating nano-sized silver colloids. J Mater Sci 40(20): 5413-5418.

87. Ilana P, Guy A, Nina P, Geoffrey G, Serguei M, et al. (2008) Sonochemical coating of silver nanoparticles on textile fabrics (nylon, polyester and cotton) and their antibacterial activity. Nanotechnology 19(24): 245705.

88. Nina P, Galina A, Guy A, Eldar E, Yuri K, et al. (2008) Depositing silver nanoparticles on/in a glass slide by the sonochemical method. Nanotechnology 19(43): 435604.

89. Tzounis L, Bangeas PI, Exadaktylos A, Petousis M, Vidakis N (2020) Three-dimensional printed Polylactic Acid (PLA) surgical retractors with sonochemically immobilized silver nanoparticles: the next generation of low-cost antimicrobial surgery equipment. Nanomaterials 10(5): 985.

90. Verhoef LA, Budde BW, Chockalingam C, García Nodar B, van Wijk AJM (2018) The effect of additive manufacturing on global energy demand: An assessment using a bottom-up approach. Energy Policy 112: 349360 .

91. Vidakis N, Petousis M, Maniadi A, Koudoumas E, Vairis A, et al. (2020) Sustainable additive manufacturing: mechanical response of acrylonitrile-butadiene-styrene over multiple recycling processes. Sustainability 12(9): 3568.

For possible submissions Click below: 